\title{
Sulfate Accumulation in a Sea Breeze/Land Breeze Circulation System
}

\author{
Glen R. Cass \\ Environmental Engineering Science Department, California Institute of Technology \\ FREDRICK H. SHAIR \\ Chemical Engineering Department, California Institute of Technology
}

\begin{abstract}
An atmospheric tracer study using $\mathrm{SF}_{6}$ was conducted on July 22 , 1977, to examine the origin of the high particulate sulfate concentrations observed in coastal Los Angeles County. It was found that the sea breeze/land breeze circulation system in the Los Angeles Basin both increases the retention time for sulfate formation in the marine environment and causes individual air parcels to make multiple passes over large coastal emissions sources. Day-old sulfur oxides emissions advected out to sea by the land breeze at night were estimated to be the largest single contributor to 24-hour average sulfate air quality over land the next day. In contrast, 24-hour average $\mathrm{SO}_{2}$ concentrations were dominated by fresh emissions from nearby sources. The overall rate of $\mathrm{SO}_{2}$ transformation to form particulate sulfur oxides along some trajectories that spent a considerable time over the ocean at night probably exceeds the rate that can be explained by known photochemical processes acting during the daylight portion of these trajectories. This suggests that appreciable aerosol formation may occur in a polluted marine environment at night.
\end{abstract}

\section{INTRODUCTION}

Sulfate aerosols contribute to regional visibility problems [Waggoner et al., 1976; White and Roberts, 1977; Trijonis and Yuan, 1978a, b; Cass, 1979] and affect the acidity of fog and rainwater [Cogbill and Likens, 1974; Likens, 1976; Liljestrand and Morgan, 1981; Waldman et al., 1982]. Since most of the sulfur oxides pollutant emissions to urban atmospheres arise in the form of gaseous $\mathrm{SO}_{2}$, there is considerable interest in the mechanisms by which $\mathrm{SO}_{x}$ emissions eventually lead to high particulate sulfate concentrations.

The land breeze/sea breeze circulation system in coastal areas results in transport of pollutants seaward at night followed by return of aged material inland the next day. This characteristic wind reversal pattern increases the potential for accumulating high particulate sulfate concentrations in the atmosphere. Pollutant concentrations are increased as the same air mass makes repeated passes over large coastal emission sources. Pollutants advected out to sea at night are retained over the ocean for long periods before they recross the coast the next morning. Even slow chemical reactions that convert $\mathrm{SO}_{x}$ gaseous emissions to particulate sulfur oxides would have time to proceed toward completion under these circumstances.

An experiment was conducted in July 1977 in the Los Angeles area designed to explore the transport of air pollutants in a land breeze/sea breeze system [Shair et al., 1982]. Sulfur hexafluoride, an inert gaseous tracer, was introduced into the exhaust of a large coastal power plant and was used to track the overnight behavior of point source plumes as they are advected offshore on the land breeze. On the two occasions studied, these point source emissions spent an average of 10 hours in the marine environment before recrossing the coast on the following day's sea breeze.

In the present paper, data collected during that experiment will be used to determine the fate of sulfur oxides air pollutants trapped in a land breeze/sea breeze system. The Los

Copyright 1984 by the American Geophysical Union.

Paper Number 3D1696.

0148-0227/84/003D-1696\$05.00
Angeles urban plume will be studied, that is, the large-scale dilute pollutant plume found downwind of the entire city caused by the co-minging of emissions from thousands of local sources. Particulate sulfur oxides and total sulfur oxides concentrations measured in the Los Angeles urban plume as it is advected out to sea at night will be related to pollutant concentrations returning inland on the next morning's land breeze. $\mathrm{SF}_{6}$ data will be used to track sulfur oxides contributed by individual point source plumes superimposed on the larger urban plume.

It will be shown that high aerosol sulfate concentrations observed in coastal Southern California can result from accumulation during repeated passes of the same air mass over local emission sources, caused by the daily land breeze/sea breeze reversals in wind direction. The rate of $\mathrm{SO}_{2}$ conversion to form particulate sulfur oxides will be estimated within air parcels that have spent an extended time within the marine environment during the night.

\section{Experimental Program}

The location chosen for study is the Santa Monica Bay coastline of Los Angeles County, shown in Figure 1. During the period July 19-26, 1977, atmospheric sulfate concentrations were measured at 2-hour intervals by low-volume sampling at two onshore locations: Redondo Beach and Lennox. On the basis of these data, sulfate concentrations in the urban plume sent seaward at night by the land breeze were determined and could be compared to the composition of air masses returned inland on the sea breeze the next day. Samples were collected on Gelman GA-1 cellulose acetate filters and analyzed for total sulfur in the aerosol phase (reported as sulfate) by $X$ ray fluorescence [Tsou et al., 1977]. The air monitoring site at Lennox was colocated with the South Coast Air Quality Management District's $\mathrm{SO}_{2}$ continuous monitoring station in that community. A time history of sulfate, sulfur dioxide, and total sulfur oxides air quality, $S_{\text {total }}$, thus can be constructed at that location. For that reason, our analyis will focus on Lennox as the receptor point of interest. 


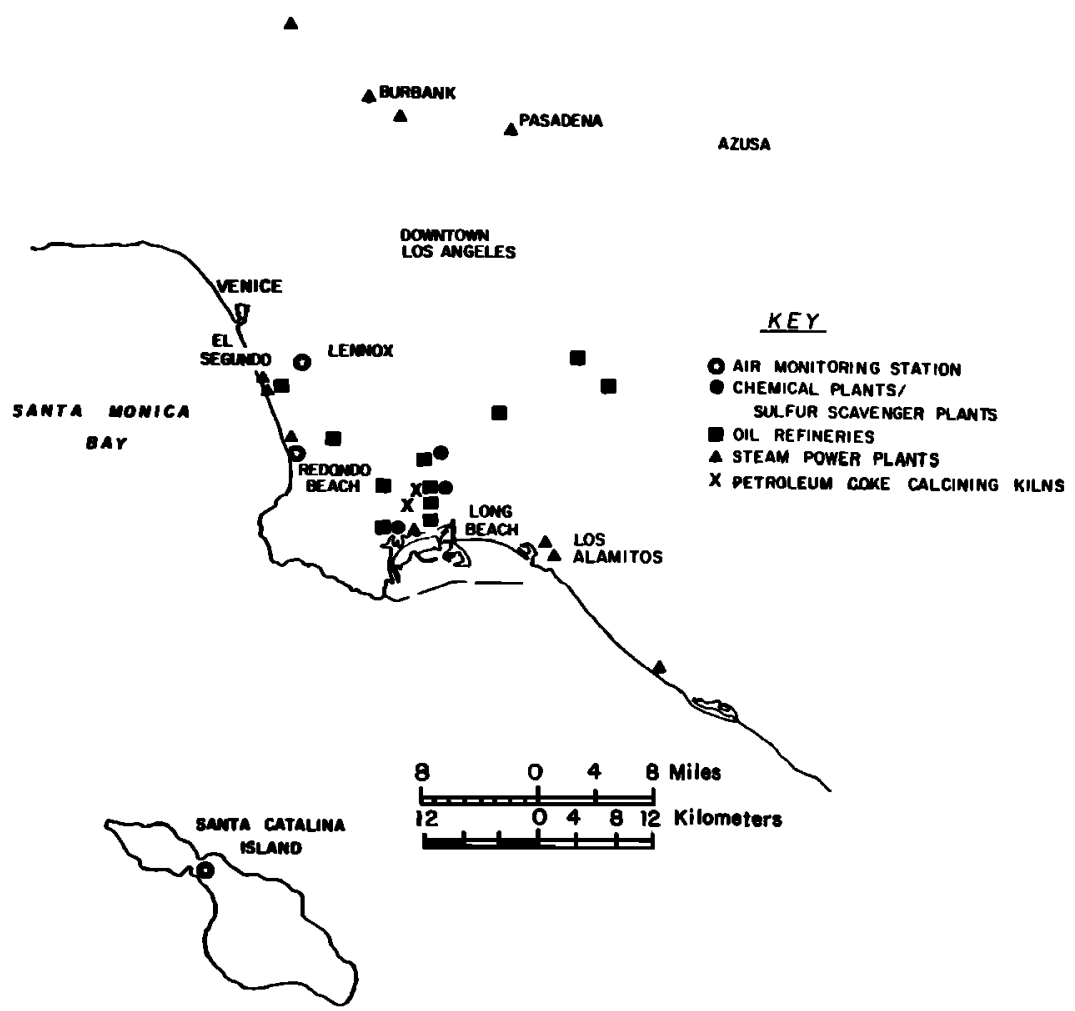

Fig. 1. Major sources of sulfur oxides emissions in the Los Angeles area.

Sulfur oxides concentrations in offshore marine air were sampled by a variety of methods. A sulfate sampling station similar to the ones at Redondo Beach and Lennox was established at Santa Catalina Island off of the Southern California coast. Flame photometric total sulfur analyzers were located at Santa Catalina Island and aboard the U.S. Navy research vessel Acania as it cruised in the Santa Monica Bay. From this sampling program, offshore sulfur oxides concentrations, $S_{\text {marine, }}$ could be determined.

Surface wind speed and direction measurements obtained from the South Coast Air Quality Management District's Redondo Beach and Venice stations were used to track the outflow and return of urban plume air masses. Measurements of inversion base height over the Santa Monica Bay were obtained from an acoustic sounder located aboard the Acania [Schacher et al., 1978]. From pollutant measurements made at Lennox during the nighttime land breeze regime, the initial concentrations of $\mathrm{SO}_{2}$ and sulfates in the urban plume air masses were determined as those air masses moved seaward. Meteorological data then can be used to estimate that portion of $S_{\text {total }}$ observed at Lennox during the next sea breeze period that originated from the previous night's seaward progress of the urban plume.

To identify the contribution to $S_{\text {total }}$ due to overnight emissions from coastal point sources near Lennox, sulfur hexafluoride tracer was injected into the stack of unit number 4 at Southern California Edison Company's El Segundo power plant. A total of $90 \mathrm{~kg}$ of $\mathrm{SF}_{6}$ was released at a continuous rate beginning at 2400 hours Pacific Daylight Time (PDT) on July 21,1977 , and ending at 0500 hours on the morning of July 22,1977 . Those tracer-labeled emissions blown out to sea at night were then observed to recross the coastline during the following day's land breeze [Shair et al., 1982]. By considering the tracer concentration observed near Lennox and the ratio of tracer released to sulfur oxides emitted by El Segundo point sources, the effect of overnight emissions from those sources on the following day's air quality at Lennox can be estimated.

\section{AIr Quality Data}

Sulfate air quality measurements made at Lennox, Redondo Beach, and Santa Catalina Island are shown in Figure 2. From July 19 through July 26, sulfate concentrations at Catalina averaged $8.9 \mu \mathrm{g} / \mathrm{m}^{3}$ (as $\mathrm{SO}_{4}{ }^{2}$ ). A long-term fluctuation about that mean value is apparent, with an amplitude of approximately $\pm 5 \mu \mathrm{g} / \mathrm{m}^{3}$ and period of about 1 week. The major departure from that pattern occurs in the afternoon of July 24, when sulfate concentrations at Catalina increased sharply from $9.0 \mu \mathrm{g} / \mathrm{m}^{3}$ up to $27.4 \mu \mathrm{g} / \mathrm{m}^{3}$ over a 2 hour time interval. Sulfur hexafluoride samplers located at Catalina indicate that $\mathrm{SO}_{x}$ emissions accompanied by a tracer release made the previous night at El Segundo passed over Catalina at that time. That was the only occasion on which transport from El Segundo to Catalina was demonstrated during this study.

Sulfate measurements made at Lennox and Redondo Beach show a distinct enrichment in pollutant concentrations above the baseline formed by marine air quality. A strong diurnal variation in sulfate concentrations is observed, with peak values typically occurring at about noontime, followed by a decline to near Santa Catalina Island levels for a short time at night. The origin of these peak $\mathrm{SO}_{4}=$ concentrations is discussed in section 5 of this paper. A longer-term pattern to onshore air quality also is observed which tends to follow that at Catalina. Successively rising daily maximum sulfate concentrations are observed from July 19 through July 22, followed by a subsequent decline over a period of several days. Sulfate concentrations at Lennox and Redondo Beach track each other closely over time, indicating that the contaminated urban air mass as it moves back and forth across the coast is fairly homogeneous in the crosswind direction along the Santa Monica Bay. 


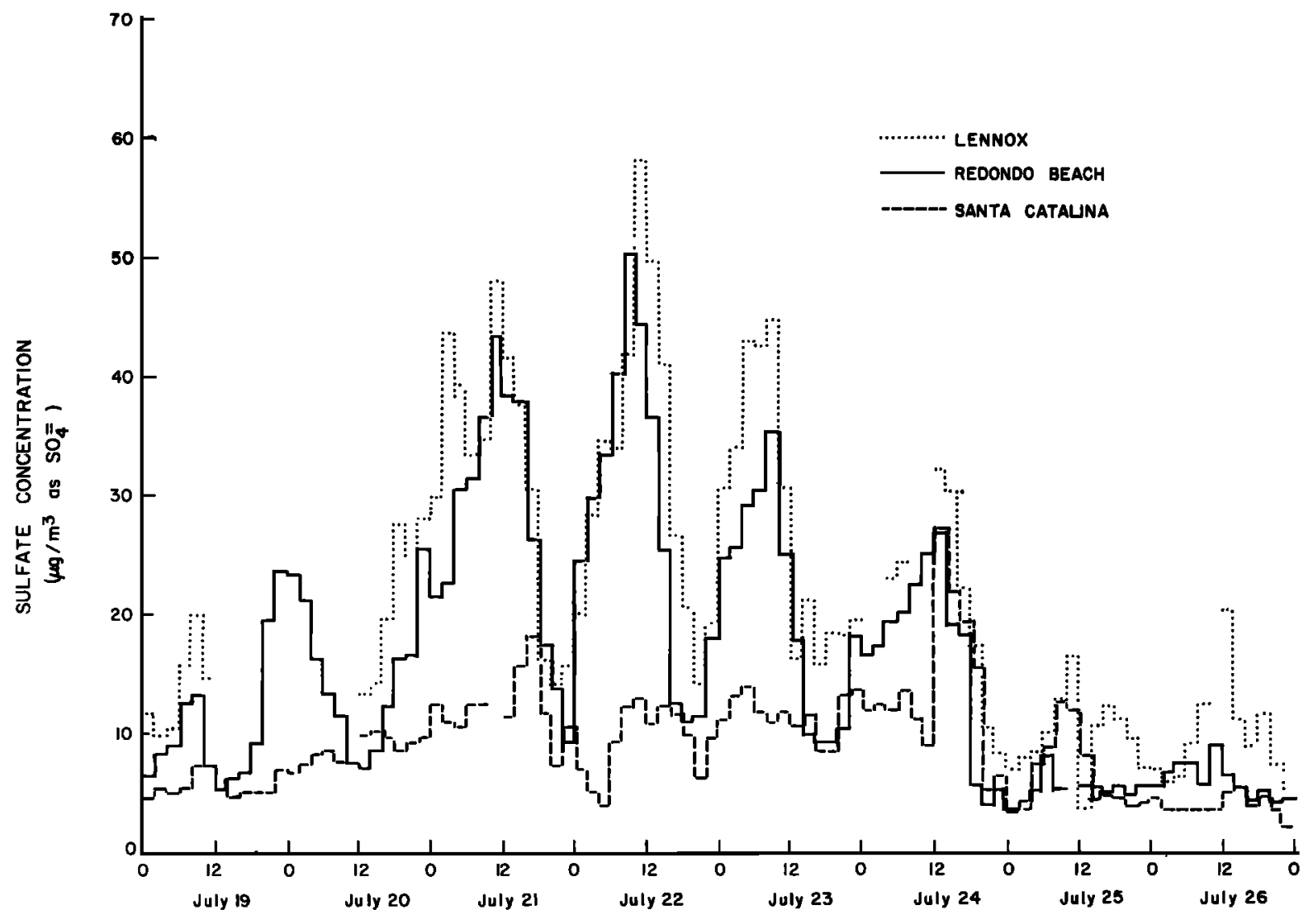

TIME

Fig. 2. Sulfate air quality measurements made at Lennox, Redondo Beach, and Santa Catalina Island.

\section{Sulfur Balance}

Sulfur balance calculations were used to explore the origin of the highest sulfate concentrations observed at Lennox, which occur on July 22. As an accounting exercise, sulfur oxides emissions from El Segundo area point sources located in the immediate vicinity of the monitoring site were tracked separately from the rest of the Los Angeles urban plume. The total sulfur oxides content of an air parcel observed over 2-hour sampling interval $j$ at Lennox was subdivided:

$$
S_{\text {totel }_{j}}=S_{\text {urban }_{j}}+S_{\text {overoight }}+S_{\text {fresh }_{j}}+S_{\text {marine }}
$$

where $S_{\text {total }}$ is total sulfur oxides concentration stated as elemental sulfur observed at Lennox during time interval $j$; $S_{u r b a n}$ is that portion of $S_{\text {total }}$ due to recirculation of the urban plume, containing pollutants previously located over the urban area upwind of our receptor point during the land breeze regime; $S_{\text {overnight, }}$ is that portion of $S_{\text {totalj }_{j}}$ due to $\mathrm{SF}_{6}$-labeled overnight emissions into the land breeze from $\mathrm{El}$ Segundo area point sources; $S_{\text {fresh }}$ is that portion of $S_{\text {tolal } 1_{j}}$ due to fresh pollutant emissions from El Segundo-area sources that occur after the end of the $S_{6}$ tracer release; $S_{\text {marines }}$ is that portion of $S_{\text {total, }}$ arising from intrusion of marine air masses over land for the first time after the urban plume has been cleared from Santa Monica Bay by continuation of a sea breeze stronger than the prior night's land breeze. A similar expression was written for total sulfur appearing as particulate sulfur oxides in each air parcel:

$$
\mathrm{SO}_{4_{\text {cotal } j}}=\mathrm{SO}_{4_{\text {urban }}}+\mathrm{SO}_{4_{\text {overnight } j}}+\mathrm{SO}_{4_{\text {ireah }_{j}}}+\mathrm{SO}_{4_{\text {marine } j}}
$$

where $\mathrm{SO}_{4 \text { losil }}$ is total aerosol sulfur oxides concentration stated as sulfur observed during time interval $j$, and the other terms identify contributors to the aerosol sulfur burden in a manner analogous to equation (1).

Equations (1) and (2) were evaluated term by term for each 2-hour sampling period $j$ at Lennox on July 22. First consider the contribution of the urban plume.

\subsection{Urban Plume}

From 2300 hours on July 21 until 0700 hours on July 22, the land breeze prevailed. All sulfur oxides advected across Lennox during that period by definition were contributed by the urban plume, and measured air quality at Lennox was used to evaluate equations (1) and (2).

Air parcels arriving after 0700 hours on the sea breeze contain some sulfur oxides contributed by recirculation of urban plume material stored at night over Santa Monica Bay. This urban plume contribution was studied by a simplified trajectory model.

Beginning with the onset of the land breeze at night, the seaward penetration, $\Delta x_{i}$, of urban plume air masses during each land breeze time interval, $i$, was calculated from the separate averages of surface wind speeds and wind directions observed at Venice and Redondo Beach. Material balances for $\mathrm{SF}_{6}$ release and return across the coastline using these wind data close almost exactly [see Shair et al., 1982], indicating that air parcel retention time over the ocean is calculated with reasonable accuracy. Inversion base data from the acoustic sounder aboard the Acania were used to obtain the depth, $h_{i}$, of the atmospheric surface mixed layer at that time. Air par- 
cels of seaward extent, $\Delta x_{i}$, height $h_{i}$, and indefinite width in the crosswind direction were successively placed over the Santa Monica Bay. Since the pollutant concentration gradient along the coast between Lennox and Redondo Beach was small on July 22 (see Figure 2), calculations are not sensitive to the width of the urban plume air parcel in the crosswind direction. As each air mass so defined passed over the Lennox air monitoring station, initial conditions for total sulfur concentration existing as sulfur dioxide and sulfates were established. It was assumed that these aged air masses are vertically well mixed to the base of the inversion.

Each of these urban plume air parcels was tracked until it recrossed Lennox on the following sea breeze. Sulfur oxides concentrations remaining in each air parcel since its initial characterization the previous night were computed with allowance for transport, pollutant dry deposition, and conversion of $\mathrm{SO}_{2}$ to form particulate matter. Since the sea breeze this day was stronger than the land breeze, polluted air parcels transported seaward during several time periods the previous night contributed to urban plume concentrations sampled over land during a single time interval the next morning.

Comparison of sulfate data taken at Redondo Beach and Lennox from late July 21 through the morning of July 22 indicates that crosswind concentration gradients on this occasion were small (see Figure 2). Consequently, crosswind diffusion within urban plume air parcels was neglected, and calculations were performed for a two-dimensional system. At 2320 hours on July 21 , the inversion base was located at 290 $\mathrm{m}$ above sea level, and the urban plume was taken to be well mixed at least to that altitude at that time. From 2400 hours on July 21 until the late afternoon of July 22, inversion base height over the ocean averaged $189 \mathrm{~m}$ above sea level and never rose to more than $260 \mathrm{~m}$ above sea level. The inversion base is not a material surface, and it does not reconcentrate pollutants as it descends. Likewise, as the inversion base rises within the $290-\mathrm{m}$ thick vertically well-mixed urban plume, any urban plume material fumigated downward from aloft would be at about the same concentration as urban plume material already below the inversion base. Thus material balance calculations for urban plume air parcels were executed based on conservation of pollutants within a well-mixed layer $189 \mathrm{~m}$ thick equal to the average inversion base height, with the understanding that inversion base fluctuations at elevations below $290 \mathrm{~m}$ would not greatly affect "urban plume" pollutant concentration within the lowest $189 \mathrm{~m}$ of the atmosphere. Point source plumes injected above the inversion base at night are by our definition not a part of the urban plume. These point source plumes are stratified and do change ground level pollutant concentrations if fumigated downward. Treatment of elevated point source plumes is described separately in section 4.3 of this analysis.

From the foregoing discussion it is concluded that the inversion base never rose high enough to include portions of the atmosphere free of urban plume material and that changes in inversion height provided no opportunity for vertical dilution of urban plume or marine air parcels. The only remaining dimension in which dilution could occur is removed by invoking the customary trajectory modeling assumption that diffusion in the direction of transport is negligible compared to gross air mass motion. Thus a moving box model for each urban plume air parcel provides an adequate approximation for use in transport calculations on this occasion.

While dilution overnight would be ineffective in reducing
$\mathrm{SO}_{2}$ and sulfate concentrations within the urban plume, sulfur oxides concentrations could be changed by chemical reaction. $\mathrm{SO}_{2}$ residing below the inversion base may react to form particulate sulfur oxides, and may be depleted by deposition at the ground or ocean's surface. The following set of competitive first-order reaction processes were used to model this process of chemical transformation and pollutant deposition:

$$
\frac{d \mathrm{SO}_{2}}{d t}=-k \mathrm{SO}_{2}-\frac{v_{g}}{h} \mathrm{SO}_{2}
$$

where $\mathrm{SO}_{2}$ is the sulfur oxides concentration existing as sulfur dioxide within an urban plume air parcel, in $\mu \mathrm{g} / \mathrm{m}^{3}$ as sulfur; $k$ is the pseudo-first-order rate of $\mathrm{SO}_{2}$ transformation to form particulate sulfur oxides due to homogeneous and heterogeneous processes combined; $v_{g}$ is the deposition velocity for $\mathrm{SO}_{2}$ at the earth's surface; $h$ is the depth of the mixed layer below the inversion base.

In a similar fashion, expressions for particulate sulfur oxides formed can be written as

$$
\frac{d \mathrm{SO}_{4}}{d t}=k \mathrm{SO}_{2}
$$

where $\mathrm{SO}_{4}$ is sulfur oxides concentration existing as particulate matter within an urban plume air parcel, in $\mu \mathrm{g} / \mathrm{m}^{3}$ as sulfur.

Customarily, $k$ would be recognized as the rate of $\mathrm{SO}_{2}$ oxidation to form sulfates. However, since the pollutant measurements used here were for total aerosol sulfur, the interpretation of $k$ must be extended to include any $\mathrm{SO}_{2}$ conversion products appearing in the aerosol phase. Slinn et al. [1978] place the deposition velocity for readily absorbed low molecular weight gases (like $\mathrm{SO}_{2}$ ) at the ocean's surface at about 1 $\mathrm{cm} / \mathrm{s}$. Garland [1976] quotes a measured $\mathrm{SO}_{2}$ deposition velocity of $0.46 \mathrm{~cm} / \mathrm{s}$ to an alkaline fresh water surface. A sulfur dioxide dry deposition velocity of $0.7 \pm 0.3 \mathrm{~cm} / \mathrm{s}$ will be used in this study. The rate of fine particle deposition to the ocean's surface is poorly understood. Davidson [1977] measured both the size distribution of Los Angeles sulfate aerosols and their deposition velocity to flat smooth surfaces. He found that Los Angeles aerosol sulfate size distributions peak at about $0.5 \mu \mathrm{m}$ diameter and that the aerosol sulfate deposition velocity to smooth flat surfaces was very low, between 0.01 and $0.1 \mathrm{~cm} / \mathrm{s}$. Laboratory experimental data on the deposition of submicron particles to water surfaces are summarized by Slinn et al. [1978, Figure 9]. For particles with diameter $0.5 \mu \mathrm{m}$ inclusive of water of hydration (typical of Los Angeles sulfate aerosols), the measured deposition velocity to water surfaces is quite low, less than $10^{-1} \mathrm{~cm} / \mathrm{s}$. Even if this sulfate aerosol were sized at $0.5 \mu \mathrm{m}$ diameter under dry conditions $(0.25 \mu \mathrm{m}$ dry radius) and subsequently grew to equilibrium size at close to $100 \%$ RH near the ocean's surface, Slinn and Slinn's [1980] theoretical curves would suggest a dry deposition velocity at or below $0.1 \mathrm{~cm} / \mathrm{s}$. The dry deposition velocity for Los Angeles sulfate aerosols probably is small compared to the $\mathrm{SO}_{2}$ dry deposition rate and will be neglected in the calculations that follow.

\subsection{Marine Air Parcels}

Transport and reaction of sulfur oxides within the marine air mass were treated in the same manner as described for the urban plume. A dividing line between marine air and the urban plume was established at the coast at 2300 hours on July 21 and was propagated seaward with the onset of the 


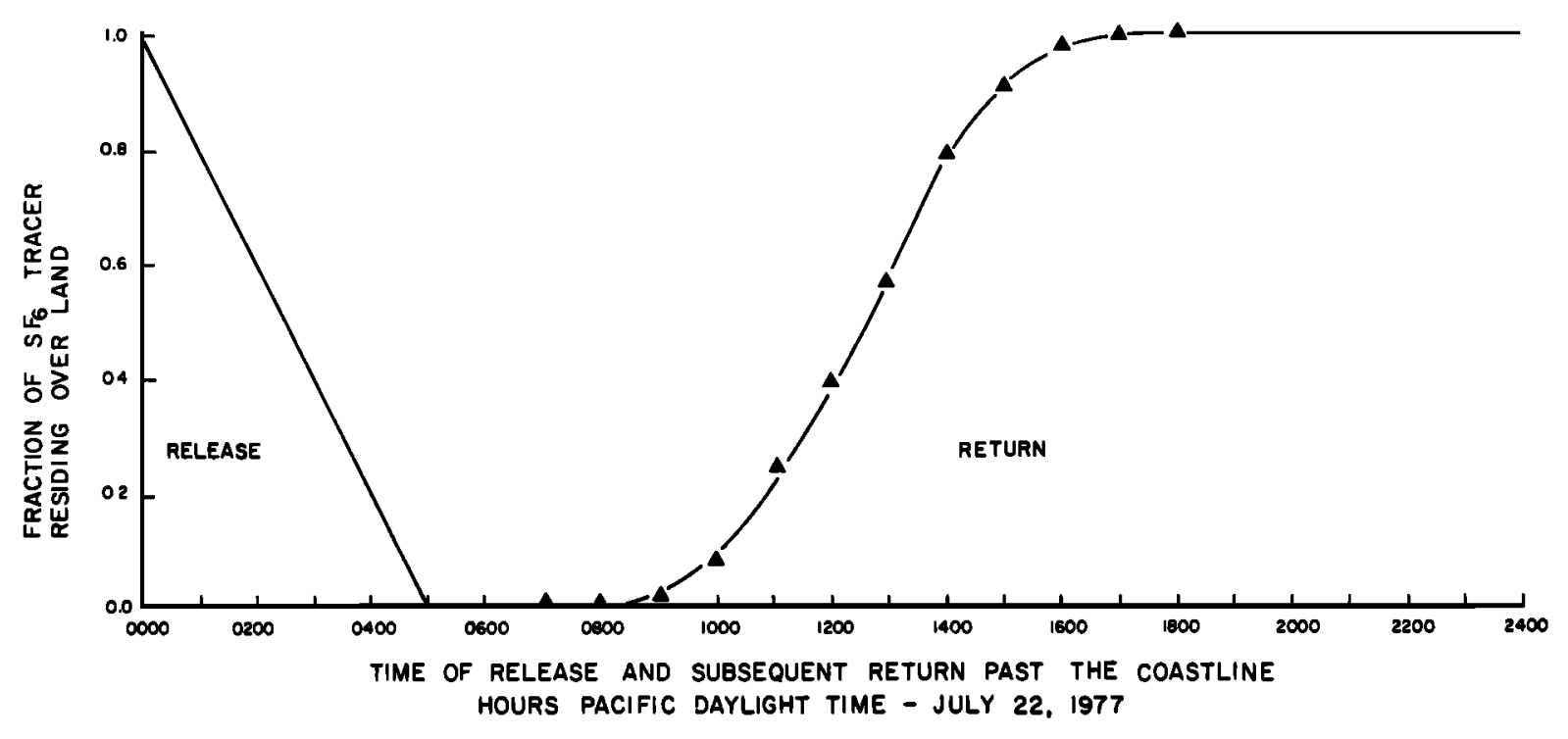

Fig. 3. $\mathrm{SF}_{6}$ tracer cumulative release and return from emissions at $\mathrm{El}$ Segundo into the nighttime land breeze regime [from Shair et al., 1982].

land breeze. To the west of this line, a large mass of marine air of uniform composition was assumed to fill the Santa Monica Bay. The assumption of a uniform composition for the marine air mass at this time is supported by the observation that Lennox, Redondo Beach, and Catalina Island all show about the same sulfate levels by 2300 hours on July 21 (see Figure 2). The initial chemical composition of this marine air mass was taken to be like that observed at Catalina Island at 2300 hours on July 21. Measurements made at Santa Catalina Island between 2300 hours and midnight indicated a total sulfur oxides concentration in marine air of $0.006 \mathrm{ppm}$ (or 7.8 $\mu \mathrm{g} / \mathrm{m}^{3}$ as sulfur) which included $10.7 \mu \mathrm{g} / \mathrm{m}^{3}$ of sulfates $(3.6$ $\mu \mathrm{g} / \mathrm{m}^{3}$ as sulfur). Simultaneous measurements made aboard the Acania indicated a total sulfur concentration of $0.01 \mathrm{ppm}$ in air over the Santa Monica Bay, which is consistent with the Catalina data to within the number of significant figures given. Once the urban plume had been completely removed from Santa Monica Bay by the sea breeze on the morning of July 22 , sulfur oxides contributed by marine air began to appear at Lennox.

\subsection{Point Source Plumes}

Overnight emissions into the land breeze from point sources at El Segundo were tagged with $\mathrm{SF}_{6}$ tracer. From tracer measurements made aboard the Acania, it was found that emissions from these elevated sources stayed aloft until about 5:30 A.M. PDT, after which fumigation to the ocean's surface occurred within a few minutes over a wide area of Santa Monica Bay [Shair et al., 1982]. This convective downmixing event has been analyzed in detail by McRae et al. [1981]. As cool air from the land flowed out to sea over a warmer ocean surface, convective mixing began to erode the air mass from below and a thermal internal boundary layer began to grow seaward from the coastline. When this growing boundary layer intercepted the elevated plume, the plume was rapidly mixed to the surface.

Trajectories calculated from surface winds indicate that emissions sent seaward at night tacked northward before recrossing the coastline the next morning. However, from a line of closely spaced $\mathrm{SF}_{6}$ samplers located at the coast, it was observed that the peak returning $\mathrm{SF}_{6}$ concentration (76 ppt hourly average) occurred between 1000 and 1100 hours at the El Segundo monitoring site. That value compares favorably to the highest hourly average $\mathrm{SF}_{6}$ concentration observed aboard the Acania (82 ppt between 0900 and 1000 hours July 22) as the ship sailed along a line headed almost directly westward from a point located several miles off of El Segundo. The implication is that the zone of highest impact of overnight emissions from Santa Monica Bay point sources recrossed the coastline the next morning near the point of pollutant origin.

The concentration of sulfur oxides later observed at Lennox due to overnight emissions was therefore estimated from measured tracer concentrations plus a knowledge of the ratio of $\mathrm{El}$ Segundo $\mathrm{SO}_{x}$ emissions to $\mathrm{SF}_{6}$ tracer released. Before mixing down to the ocean's surface, $\mathrm{SO}_{2}$ in the elevated source plume could react to form particulate sulfur oxides, but no removal processes occur due to deposition at the earth's or ocean's surface. After fumigation, both surface deposition and $\mathrm{SO}_{2}$ oxidation would serve to alter pollutant composition and concentration. Total sulfur oxides concentrations observed at Lennox the next morning owing to overnight emissions from El Segundo were taken to be equal to that computed from tracer concentrations and the $\mathrm{SF}_{6}$ tracer to $\mathrm{SO}_{x}$ emission ratio, less any $\mathrm{SO}_{2}$ surface deposition. The plume rise characteristics for the dominant $\mathrm{SO}_{x}$ source at the El Segundo refinery (a fluid catalytic cracker) were compared to the plume rise characteristics of the El Segundo power plant unit 4 at half load and at $75 \%$ load. It was found that these two plumes should travel at similar elevations. The ratio of El Segundo point source $\mathrm{SO}_{x}$ emissions to $\mathrm{SF}_{6}$ released was estimated at 103:1 on a volume basis, considering the $\mathrm{SF}_{6}$ as a tracer for all $\mathrm{SO}_{x}$ emitted from both El Segundo area power plants and the adjacent petroleum refinery.

In a similar fashion, the contribution to daytime sulfate air quality owing to overnight emissions from coastal point

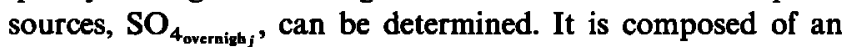
increment due to the primary emissions of sulfates from those sources, plus sulfates formed from $\mathrm{SO}_{2}$ oxidation during the 


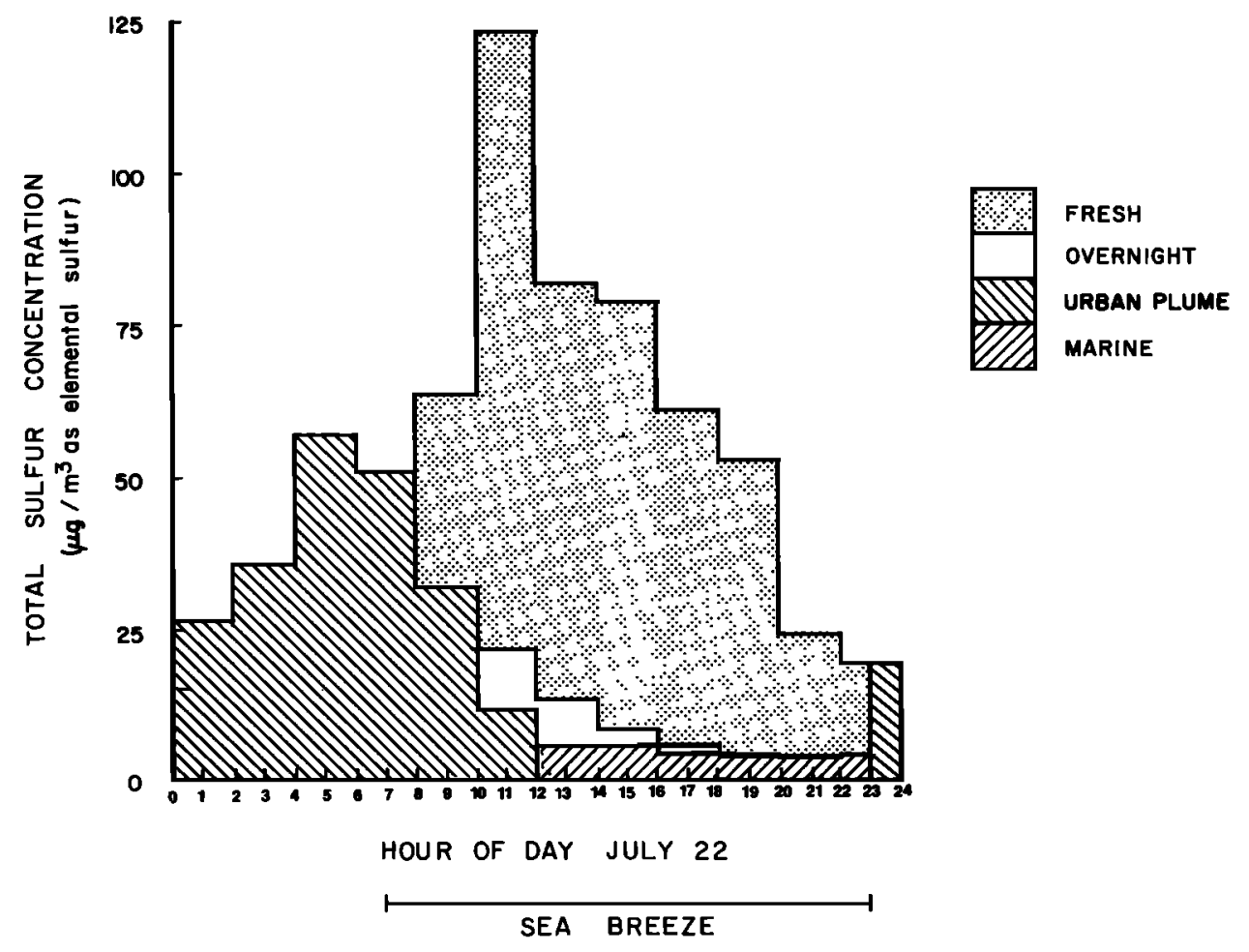

Fig. 4. Total sulfur concentrations observed at Lennox, July 22, 1977.

period while the plumes were isolated aloft, plus sulfates formed from $\mathrm{SO}_{2}$ oxidation after the plumes had fumigated to the ocean's surface. The initial fraction of $\mathrm{SO}_{x}$ emissions, $f_{s}$, evolved directly as sulfates from utility fuel combustion and refinery processes was taken as 0.03 or $3 \%$ of total $\mathrm{SO}_{x}$ emissions based on data given by Hunter and Helgeson [1976].

Mass balance calculations for $\mathbf{S F}_{6}$ release and return are shown in Figure 3, from which the residence time for chemical reaction of plume segments over the ocean was estimated. Again, the first material emitted into the land breeze was assumed to be the last material returned to land.

\subsection{Fresh Emissions}

$\mathrm{SF}_{6}$ tracer insertion into the point source plume ceased at 5:00 A.M., near the end of the nighttime land breeze. Fresh sulfur oxides emissions occurring after the end of the $\mathrm{SF}_{6}$ release also influenced Lennox air quality. An analysis of wind flow data on the morning of July 22 indicated that emissions into the sea breeze at El Segundo were transported directly toward Lennox, and transport times, $\Delta t$, from El Segundo to Lennox were determined for each 2-hour air sampling interval. The contribution to Lennox sulfur oxides air quality due to fresh emissions fr Jm sources in the vicinity of that monitoring site was taken to be equal to the difference between total $\mathrm{SO}_{x}$ observed and contributions from other known sources. That is,

$$
\mathbf{S}_{\text {fresh }_{j}}=\mathbf{S}_{\text {total }_{j}}-\mathbf{S}_{\text {urban }}-\mathbf{S}_{\text {marine }_{j}}-\mathbf{S}_{\text {overnight }_{j}}
$$

The maximum sulfate contribution due to fresh emissions from nearby sources is taken to be

$$
\mathrm{SO}_{4_{\text {fresh }}}=\mathrm{S}_{\mathrm{fresh}_{\mathrm{j}}}\left(f_{s}+\left(1-f_{s}\right)\left(1-e^{-k \Delta \mathrm{d} j}\right)\right)
$$

assuming that these emissions occurred from elevated sources so close to the receptor point that ground level deposition can be neglected during most of the transport time from source to receptor.

\subsection{Sulfur Balance Calculations}

The procedure described for evaluating equations (1) and (2) yields a system of two sulfur balance equations involving two unknowns, $\mathrm{S}_{\text {fresh }}$ and the effective average $\mathrm{SO}_{2}$ transformation rate, $k$. Within each air parcel arriving at Lennox during the sea breeze portion of July 22 , a trial value for $k$ was assumed. The total sulfur balance (equation (1)) was used to calculate $S_{\text {fresh }}$. That value of $S_{\text {fresh, }}$ was inserted into the sulfate balance (equation (2)), and an estimate of $\mathrm{SO}_{4}$ (otal, was obtained and compared with the measured value of $\mathrm{SO}_{4_{\text {lotal } 1 j}}$ The system of equations was solved by successive substitution of $k$ values until measured and calculated sulfate concentrations agreed.

\section{Discussion of Results}

Total sulfur oxides concentrations observed at Lennox on July 22 are shown in Figure 4. On a 24-hour average basis, contributors to that pollutant loading included: (1) $60 \%$ fresh emissions from nearby sources, (2) $33 \%$ urban plume sulfur oxides recirculated from over the urban area by the land breeze/sea breeze reversal, (3) $4 \%$ marine sulfur oxides, and (4) $3 \%$ overnight point source emissions tagged with $\mathrm{SF}_{6}$. The dominant contribution from fresh emissions is to be expected because Lennox was directly in the path of the plumes from $\mathrm{El}$ Segundo point sources during most of the sea breeze portion of July 22.

While total sulfur oxides air quality was dominated by fresh emissions from nearby sources, sulfate concentrations were due largely to the oldest material in the atmosphere. Measurements at Lennox on July 22 yielded a 24 hour average sulfate concentration of $32.3 \mu \mathrm{g} / \mathrm{m}^{3}$. Figure 5 shows that that 24 hour average consisted of (1) $49 \%$ day-old urban plume material, 

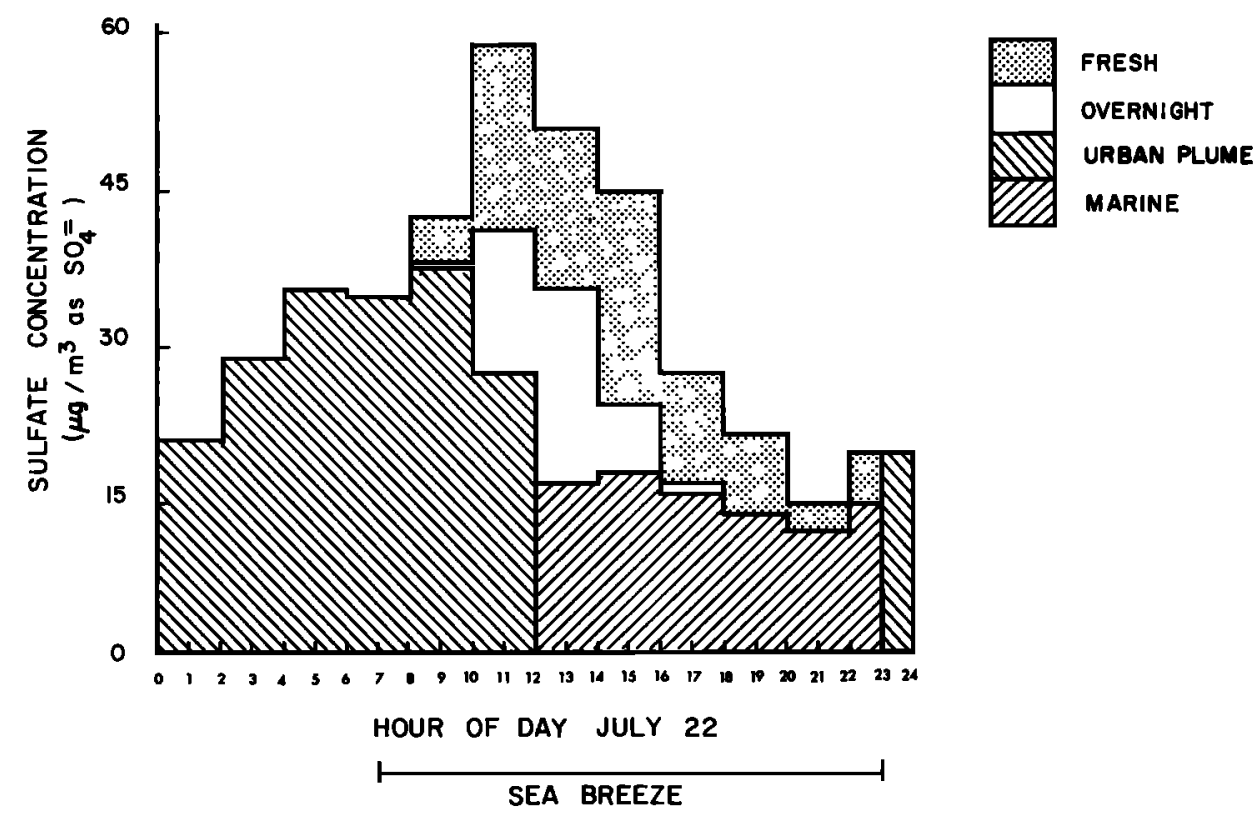

Fig. 5. Sulfate concentrations observed at Lennox, July 22, 1977.

(2) $20 \%$ marine material, (3) $20 \%$ fresh emissions, and (4) $11 \%$ overnight point source emissions tagged with $\mathrm{SF}_{6}$.

One reason for the relatively modest impact of fresh emissions on Lennox sulfate air quality is found in the initial chemical composition of those fresh $\mathrm{SO}_{x}$ emissions. Nearly all of the fresh $\mathrm{SO}_{x}$ emissions are evolved from their source as $\mathrm{SO}_{2}$. In the late morning and early afternoon of July 22, transport times from El Segundo to Lennox were less than 1 hour. Sulfate formation was slow enough so that fresh $\mathrm{SO}_{x}$ emissions still existed predominantly as $\mathrm{SO}_{2}$ at the time that they crossed the Lennox monitoring site. In contrast, urban plume and marine air parcels carried a significant fraction of their total sulfur oxides concentrations as sulfates at the time of their initial characterization. Over long retention times, additional sulfates formed by oxidation of $\mathrm{SO}_{2}$. Meanwhile, total sulfur in marine and urban plume air parcels declined due to surface deposition of $\mathrm{SO}_{2}$. The result is that these aged air masses were major contributors to observed sulfate concentrations in spite of their reduced importance to total sulfur oxides concentrations. The sea breeze/land breeze circulation system made possible the long retention times needed for sulfate accumulation in urban plume air parcels.

A second effect of the sea breeze/land breeze circulation system is to increase sulfate concentrations due to multiple passes of the same air mass over the same emission sources. This feature is most clearly illustrated by considering the peak sulfate concentrations that occurred at Lennox between 1000 and 1200 hours on July 22. The air mass passing Lennox during that time interval contained neither the highest urban plume contribution observed nor the highest overnight point source or fresh emissions impacts observed over a 2 hour period. The superposition of pollutant contributions from several distinct passes of the same air mass over coastal point sources, however, was sufficient to accumulate the high concentrations observed at that time.

From solution of the system of sulfur balance equations, a series of estimates was made of the rate of $\mathrm{SO}_{2}$ oxidation within air parcels arriving at Lennox on July 22 . Using the nominal parameter values measured during the experiment, the estimated value for $k$ was greater than zero at all times (as shown in column 2 of Table 1), indicating that sulfate formation was occurring over time.

In Table 1, individual determinations of $k$ are compared to experimental results obtained in the Los Angeles atmosphere by Roberts [1975] during the same season of a previous year. The results of the present study are in the same range as those of Roberts [1975] but with a somewhat lower average value. The overall average of the $\mathrm{SO}_{2}$ oxidation rates shown in column 2 of Table 1 was $5.3 \%$ per hour. That value compares favorably to the average Los Angeles summertime $\mathrm{SO}_{2}$ oxidation rate of $6 \%$ per hour estimated from the sulfate air quality model validation study by Cass $[1978,1981]$ and is within the range of $4 \%$ per hour to $10 \%$ per hour inferred from statistical analysis of Los Angeles ambient air quality data by Henry and Hidy [1979].

Considerable scatter in oxidation rate estimates is apparent both in this study and in the experiments conducted by $R o$ berts [1975], even for air parcels with consecutive times of arrival at the monitoring sites of interest. This may be due in part to a diurnal variation in $\mathrm{SO}_{2}$ oxidation rate, but another likely explanation lies in the nature of the experimental conditions encountered in these field studies. Fairly small changes in measured transport parameters, pollutant concentrations, and deposition velocities can lead to correspondingly larger percentage changes in reaction rate estimates. For example, a $20 \%$ reduction in sulfate concentration observed at Lennox between 1400 and 1600 hours on July 22 would have reduced the estimated $\mathrm{SO}_{2}$ oxidation rate from $14 \%$ per hour down to $7.8 \%$ per hour. The calculation scheme further forces agreement between calculated and measured total sulfur oxides concentrations, with the result that uncertainties in the $\mathrm{SO}_{2}$ concentration measurements contribute to scatter in the $\mathrm{SO}_{2}$ oxidation rate estimates. The simplified transport assumptions used in this analysis caused by the lack of data on winds aloft, for example, also introduce uncertainties into these calculations. To study the effect of the propagation of uncertainties on the $\mathrm{SO}_{2}$ oxidation rate estimates, a formal error analysis was conducted. 
TABLE 1. Comparison of $\mathrm{SO}_{2}$ Oxidation Rates Calculated in This Study to Values Previously Reported for Trajectories in the Los Angeles Basin at That Time of Year

\begin{tabular}{|c|c|c|c|c|c|c|}
\hline $\begin{array}{l}\text { Time of Arrival } \\
\text { at Trajectory } \\
\text { End Point, } \\
\text { PDT }\end{array}$ & $\begin{array}{c}\text { July 22, } 1977 \\
\text { Ending at Lennox } \\
\text { (Using Nominal } \\
\text { Values From This } \\
\text { Study), } k \% / \mathrm{hr}\end{array}$ & $\begin{array}{c}\text { July 22, } 1977 \\
\text { Ending at Lennox } \\
\text { (Mean } \pm \text { Standard } \\
\text { Error From } \\
\text { Uncertainty Analysis; } \\
\text { This Study), } \\
k \% / h r\end{array}$ & $\begin{array}{l}\text { Probability That No } \\
\mathrm{SO}_{2} \text { Oxidation is } \\
\text { Needed to Explain } \\
\text { Observations } \\
\text { at Lennox } \\
\text { on July 22, } 1977\end{array}$ & $\begin{array}{c}\text { July 10, } 1973 \\
\text { Ending at } \\
\text { Pasadena } \\
\text { [Roberts, 1975], } \\
k \% / h r\end{array}$ & $\begin{array}{c}\text { July } 25,1973 \\
\text { Ending at } \\
\text { Pasadena } \\
\text { [Roberts, 1975], } \\
\boldsymbol{k} \% / \mathrm{hr}\end{array}$ & $\begin{array}{c}\text { July } 26,1973 \\
\text { Ending at } \\
\text { Pasadena } \\
\text { [Roberts, 1975], } \\
k \% / \mathrm{hr}\end{array}$ \\
\hline $\begin{array}{r}800 \\
900 \\
1000\end{array}$ & 1.4 & $1.5 \pm 1.6$ & 0.33 & & . & \\
\hline 1100 & 6.3 & $4.6 \pm 2.9$ & 0.03 & & & 5.2 \\
\hline 1200 & & & & 1.2 & & 5.1 \\
\hline 1300 & 10.1 & $7.9 \pm 5.8$ & 0.01 & 3.0 & 12.1 & 8.1 \\
\hline 1400 & & & & 10.0 & 8.6 & 4.6 \\
\hline $\begin{array}{l}1500 \\
1600\end{array}$ & 14.0 & $10.8 \pm 10.0$ & 0.03 & 14.6 & 10.3 & \\
\hline $\begin{array}{l}1700 \\
1800\end{array}$ & 6.9 & $4.5 \pm 4.4$ & 0.13 & & & \\
\hline $\begin{array}{l}1900 \\
2000\end{array}$ & 2.7 & $1.8 \pm 1.9$ & 0.28 & & & \\
\hline 2100 & 0.8 & $0.8 \pm 0.9$ & 0.46 & & & \\
\hline 2300 & 4.6 & $2.6 \pm 2.4$ & 0.10 & & & \\
\hline Average value & 5.8 & 4.3 & & 7.2 & 10.3 & 5.8 \\
\hline
\end{tabular}

*Based on 100 perturbed sets of experimental data.

Data used to support the $\mathrm{SO}_{2}$ oxidation rate calculations were examined, and an estimate of the standard error of each parameter value was made. Sackinger et al. [1982] have placed error bounds on $\mathrm{SF}_{6}$ mass balance calculations during this experiment and report values for 1 standard error in measured parameters as follows: wind speed (hence transport time) $\pm 25 \%, \mathrm{SF}_{6}$ concentration $\pm 30 \%$, and mixing depth $\pm 40 \%$. To this we have added a $\pm 20 \%$ uncertainty in measured pollutant concentrations, an $\mathrm{SO}_{2}$ dry deposition velocity of $0.7 \pm 0.3 \mathrm{~cm} / \mathrm{s}$ as explained previously, $a \pm 100 \%$ uncertainty in the fraction of the sulfur oxides emissions released in the form of primary sulfates (with $f_{s}$ not allowed to become negative). The $\mathrm{SF}_{6}$ emission rate during the experiment was measured very accurately and is assumed to be known exactly. The El Segundo point source $\mathrm{SO}_{\boldsymbol{x}}$ emissions estimate was taken to be known to $\pm 20 \%$, equivalent to approximately a $\pm 100 \%$ uncertainty in the $\mathrm{SO}_{x}$ emissions contributed by the petroleum refinery (fuel consumption by the power plants is known).

One hundred sets of perturbed input data were prepared for each trajectory calculation by using a Gaussian random number generator keyed to the foregoing estimates of the standard error of each nominal parameter value. Then values of the effective $\mathrm{SO}_{2}$ oxidation rate, $k$, were computed, using each of the perturbed data sets.

Results of this error propagation analysis are shown in Table 1 , columns 3 and 4 . In column 3 it is seen that the average value of $k$ from 100 trials per trajectory is about the same or slightly lower than the value of $k$ obtained in column 2 of that table from direct use of the nominally measured parameter values. Derivation of the average value of $k$ in column 3 of Table 1 from the value of $k$ obtained in column 2, using the nominally measured parameter values, probably occurs because computation of $k$ involves functions that are not linear in all of the variables.
The standard error of the population of $k$ values obtained from the uncertainty analysis is given adjacent to the mean values of $k$ shown in column 3 of Table 1 . These error bounds are about the same size as the nominal value of $k$ itself. The probability that no $\mathrm{SO}_{2}$ oxidation occurred along each trajectory is given in column 4 of Table 1 and was estimated by counting the fraction of each set of 100 trials that require no $\mathrm{SO}_{2}$ oxidation to meet or exceed measured sulfate levels.

From the analysis of uncertainties in the calculation of $\mathrm{SO}_{2}$ oxidation rates, the following conclusions can be drawn. First, $\mathrm{SO}_{2}$ oxidation is almost definitely occurring along those trajectories terminating at Lennox between 1000 hours and 1800 hours PDT on July 22, 1977. The mean value of $k$ for each of those trajectory data sets falls between $4.5 \%$ hour $^{-1}$ and $10.8 \%$ hour ${ }^{-1}$, and the probability that no $\mathrm{SO}_{2}$ oxidation occurred is very low. In contrast, the air parcels arriving at Lennox prior to 1000 hours and after 1800 hours PDT show much lower $\mathrm{SO}_{2}$ oxidation rates, on the order of $1-2 \%$ per hour with a much higher chance that no $\mathrm{SO}_{2}$ oxidation occurred within those air parcels.

At first glance, Table 1 appears to suggest that there is a diurnal variation in the $\mathrm{SO}_{2}$ oxidation rate, with high values during the daytime suggesting a photochemical sulfate formation route. This may be true, but the appearance could be deceiving. The time periods listed in Table 1 are for trajectory arrival at Lennox. Trajectories arriving at Lennox between 1000 hours and 1800 PDT hours actually originated at night and spent about half of their travel time within the marine environment at night. This is readily confirmed by reference to Figures 4 and 5 . The trajectories showing a high $\mathrm{SO}_{2}$ conversion rate that arrive at Lennox between 1000 hours and 1800 PDT hours are the trajectories that contain the $\mathrm{SF}_{6}$-marked "overnight" point source emissions that were known to have been transported out to sea at night. Trajectories arriving after 1800 hours contain marine air accompanied by very fresh 
emissions introduced into the sea breeze during the daytime upwind of Lennox only a short time before reaching that receptor site. The low reactivity trajectory arriving in the early morning between 0800 and 1000 hours likewise contains very little of the sulfur oxides stored over the ocean at night, as shown by the very low $\mathrm{SF}_{6}$ concentrations present in that air parcel. In summary, the high reaction rates observed in air parcels arriving at Lennox between 1000 and 1800 hours could be due to daylight photochemical processes and/or to processes occurring in the marine environment at night, while the low reactivity trajectories generally were not involved in the overnight pollutant storage phenomena over Santa Monica Bay.

Further insight into whether or not photochemical processes alone would be sufficient to explain the observed $\mathrm{SO}_{2}$ conversion to aerosol sulfates during this experiment can be gained by comparing the magnitude of the estimated values of $k$ in Table 1 to the rate of known photochemical $\mathrm{SO}_{2}$ oxidation processes. Because of the fairly large uncertainties in the $\mathrm{SO}_{2}$ oxidation rate estimates given in column 3 of Table 1 , these comparisons must be stated in a probabilistic sense, but one can identify the most probable answer to questions based on such comparisons. Sander and Seinfeld [1976] state that the maximum possible $\mathrm{SO}_{2}$ oxidation rate in the Los Angeles atmosphere caused by known homogeneous gas phase photochemical processes alone is $4.5 \%$ /hour. The high reactivity trajectory arriving at Lennox between 1400 hours and 1600 hours PDT suggests a nominal actual $\mathrm{SO}_{2}$ oxidation rate of $14.0 \%$ /hour (column 2 of Table 1 ) or $10.8 \%$ /hour (column 3 of Table 1), both of which are much higher than the $4.5 \%$ /hour that might be generated by known photochemical processes. The error analysis shows that with a probability of $70 \%$, the average $\mathrm{SO}_{2}$ oxidation rate did meet or exceed $4.5 \%$ /hour along that trajectory.

The likelihood that photochemical oxidation alone would explain the rapid buildup of aerosol sulfur along this trajectory is even more remote when one considers that much of the transport studied here occurred at night. The implication is that some other chemical mechanism, perhaps involving heterogeneous processes on or within wetted particles, is adding to the formation of particulate sulfur oxides in the Los Angeles atmosphere or that currently unknown photochemical processes are at work. Evidence that liquid phase $\mathrm{SO}_{2}$ conversion was possible on this occasion is provided by National Weather Service [U.S. Department of Commerce, 1977] records at Los Angeles International Airport (adjacent to Lennox). Those data show relative humidities above the deliquescence point of ammonium sulfate throughout the early morning hours of July 22, intermittent cloud cover, and a cloud level ceiling of 700 feet $(213 \mathrm{~m}$, near the top of the pollutant layer) at 0400 hours PST.

Since the measurements made in this study were for total sulfur in the gaseous and aerosol phase, actual oxidation of sulfur (IV) to sulfur (VI) need not have occurred for the conversion of $\mathrm{SO}_{2}$ to particulate matter to have been observed. One possible contributor to the accumulation of particulate sulfur oxides could lie in the formation of stable aqueous organic sulfur (IV) complexes as observed in Los Angeles coastal fogs by Munger et al. [1983].

Acknowledgments. The advice and assistance furnished throughout this program by Charles Bennett is gratefully acknowledged. This work was supported by the California Air Resources Board under agreement A6-202-30.

\section{REFERENCES}

Cass, G. R., Methods for sulfate air quality management with applications to Los Angeles, PhD thesis, Calif. Inst. of Technol., Pasadena, 1978.

Cass, G. R., On the relationship between sulfate air quality and visibility with examples in Los Angeles, Atmos. Environ., 13, 10691084, 1979.

Cass, G. R., Sulfate air quality control strategy design, Atmos. Environ., 15, 1227-1249, 1981.

Cogbill, C. V., and G. E. Likens, Acid precipitation in the northeastern United States, Water Resour. Res., 10, 1133-1137, 1974.

Davidson, C. I., Deposition of trace metal-containing aerosols on smooth, flat surfaces and on wild oat grass, Ph.D thesis, Calif. Inst. of Technol., Pasadena, 1977.

Garland, J. A., Dry deposition of $\mathrm{SO}_{2}$ and other gases, in AtmosphereSurface Exchange of Particulate and Gaseous Pollutants (1974), edited by R. J. Engelmann and G. A. Sehmel, Technical Information Center, Office of Public Affairs, U.S. Energy Research and Development Administration, 1976.

Henry, R. C., and G. M. Hidy, Multivariate analysis of particulate sulfate and other air quality variables by principal components, I, Annual data from Los Angeles and New York, Atmos. Environ., 13, 1581-1596, 1979.

Hunter, S. C., and N. L. Helgeson, Control of oxides of sulfur from stationary sources in the South Coast Air Basin of California, Doc. Number KVB 5802-432, KVB Inc., Tustin, California, 1976.

Likens, G. E., Acid precipitation, Chem. Eng. News, 54(48), 29-44, 1976.

Liljestrand, H. M., and J. J. Morgan, Spatial variations of acid precipitation in Southern California, Environ. Sci. Technol., 15, 333338, 1981.

McRae, G. J., F. H. Shair, and J. H. Seinfeld, Convective downmixing of plumes in a coastal environment, J. Appl. Meteorol., 20, 13121324, 1981.

Munger, J. W., D. J. Jacob, J. M. Waldman, and M. R. Hoffmann, Fogwater chemistry in an urban atmosphere, J. Geophys. Res., 88, 5109-5121, 1983.

Roberts, P. T., Gas-to-particle conversion: Sulfur dioxide in a photochemically reactive system, Ph.D thesis, Calif. Inst. of Technol., Pasadena, 1975.

Sackinger, P. A., D. D. Reible, and F. H. Shair, Uncertainties associated with the estimation of mass balances and Gaussian parameters from atmospheric tracer studies, J. Air Pollut. Control Assoc., 32, 720-724, 1982.

Sander, S. P., and J. H. Seinfeld, Chemical kinetics of homogeneous oxidation of sulfur dioxide, Environ. Sci. Technol., 10, 1114-1123, 1976.

Schacher, G. E., C. W. Fairall, K. L. Davidson, and T. M. Houlihan, Experimental investigation of the marine boundary layer in support of air pollution studies in the Los Angeles air basin, Rep. NPS 61-78-002, Naval Post Graduate School, Monterey, Calif., 1978.

Shair, F. H., E. J. Sasaki, D. E. Carlan, G. R. Cass, W. R. Goodin, J. G. Edinger, and G. E. Schacher, Transport and dispersion of airborne pollutants associated with the land breeze-sea breeze system, Atmos. Environ., 16, 2043-2053, 1982.

Slinn, W. G. N., L. Hasse, B. B. Hicks, A. W. Hogan, D. Lal, P. S. Liss, K. O. Munnich, G. A. Sehmel, and O. Vittori, Some aspects of the transfer of atmospheric trace constituents past the air-sea interface, Atmos. Environ., 12, 2055-2087, 1978.

Slinn, S. A., and W. G. N. Slinn, Predictions for particle deposition on natural waters, Atmos. Environ., 14, 1013-1016, 1980.

Trijonis, J., and K. Yuan, Visibility in the southwest: an exploration of the historical data base, Doc. EPA-600/3-78-039, U.S. Environ. Prot. Agency, Research Triangle Park, N. C., 1978a.

Trijonis, J., and K. Yuan, Visibility in the northeast: Long-term visibility trends and visibility/pollutant relationships, Doc. EPA-600/378-075, U.S. Environ. Prot. Agency, Research Triangle Park, N. C., $1978 b$.

Tsou, G., D. Gibbons, D. W. Davis, and S. Sarkissian, Sulfate data at Lennox, Redondo Beach, and Santa Catalina Island in July 1977, report, Aerosol Lab., Calif. Air Res. Bd., El Monte, Calif., October 1977.

U.S. Department of Commerce, Local climatological data, July 1977, Los Angeles, California, National Oceanic and Atmospheric Administration, Asheville, N. C., 1977. 
Waggoner, A. P., A. J. Vanderpol, R. J. Charlson, S. Larsen, L. Granat, and C. Tragardh, Sulphate-light scattering ratio as an index of the role of sulfur in tropospheric optics, Nature, 261, 120$122,1976$.

Waldman, J. M., J. W. Munger, D. J. Jacob, R. C. Flagan, J. J. Morgan, and M. R. Hoffmann, Chemical composition of acid fog, Science, 218, 677-680, 1982.

White, W. H., and P. T. Roberts, On the nature and origins of visibility-reducing aerosols in the Los Angeles air basin, Atmos. Environ., 11, 803-812, 1977.
G. R. Cass, Environmental Engineering Science Department, California Institute of Technology, Pasadena, CA 91125.

F. H. Shair, Chemical Engineering Department, California Institute of Technology, Pasadena, CA 91125.

(Received November 12, 1982;

revised October 11, 1983; accepted October 17, 1983.) 